\title{
Different Evolutions of the Microstructure, Texture, and Mechanical Performance During Tension and Compression of 316L Stainless Steel
}

\author{
MOUSTAFA EL-TAHAWY, PÉTER JENEI, TAMÁS KOLONITS, GIGAP HAN, \\ HYEJI PARK, HEEMAN CHOE, and JENÖ GUBICZA
}

\begin{abstract}
The tensile and compressive behaviors of $316 \mathrm{~L}$ stainless steel at room temperature were compared. The differences between the stress-strain responses during tension and compression were explained by the different evolutions of the texture, defect structure, and phase composition. It was found that up to true strain of $\sim 25$ pct the flow stress during tension was only slightly higher (by $\sim 40 \mathrm{MPa}$ ) than that during compression, which can be explained by the different textures of the two types of specimens. On the other hand, between the strains of 25 and $50 \mathrm{pct}$, the strain hardening for tension was much higher, which resulted in a $\sim 200 \mathrm{MPa}$ larger flow stress in the tensile-tested specimen at 50 pet strain. It was revealed that the higher flow stress in tension was caused by the harder texture, the higher dislocation density, and the larger fraction of martensite phase.
\end{abstract}

https://doi.org/10.1007/s11661-020-05782-5

(c) The Author(s) 2020

\section{INTRODUCTION}

316L stainless steel exhibits desirable functional properties such as very good ductility, excellent corrosion resistance, low susceptibility to neutron absorption, good thermal stability, and a high biocompatibility. ${ }^{[1-3]}$ Thus, $316 \mathrm{~L}$ steel is used in many different applications, such as in nuclear power plants ${ }^{[4]}$ and marine environment, ${ }^{[5]}$ or for the production of orthopedic implants. ${ }^{[6]}$

Martensitic phase transformation is one of the important features of metastable austenitic stainless steels (e.g., $316 \mathrm{~L}, \quad 301 \mathrm{LN}$, and $304 \mathrm{~L}$ steels), ${ }^{[7-11]}$ as the face-centered cubic (fcc) $\gamma$-austenite structure usually exhibits a martensitic phase transformation during plastic deformation. The type and amount of deformation-induced martensite depends on the type and degree of plastic straining, the deformation temperature, and the stacking fault energy (SFE), which is strongly influenced by the chemical composition of the steel. ${ }^{[11-14]}$ In the literature, two paths were reported for martensitic transformation in steels. During the first

MOUSTAFA EL-TAHAWY is with the Department of Physics, Faculty of Science, Tanta University, Tanta 31527, Egypt. PÉTER JENEI, TAMÁS KOLONITS, and JENÖ GUBICZA are with the Department of Materials Physics, Eötvös Loránd University, P.O.B. 32, Budapest 1518, Hungary. Contact e-mail: jeno.gubicza@ttk.elte.hu GIGAP HAN, HYEJI PARK, and HEEMAN CHOE are with the School of Materials Science and Engineering, Kookmin University, 77 Jeongneung-ro, Seongbuk-gu, Seoul 136-702, Republic of Korea.

Manuscript submitted December 31, 2019.

Article published online May 6, 2020 one, the $\gamma$-austenite structure transforms directly to $\alpha^{\prime}$-martensite with body-centered cubic (bcc) structure $^{[9,15,16]}$. The second path of martensitic transformation takes place through an intermediate phase ( $\varepsilon$-martensite) that has a hexagonal close-packed (hcp) crystal structure. ${ }^{[7,9,16-20]}$ It was found that $\varepsilon$-martensite is formed during the beginning of plastic deformation and transforms to $\alpha^{\prime}$-martensite with further deformation. A recently published work performed on $316 \mathrm{~L}$ steel showed that $\gamma$-austenite transformed directly to $\alpha^{\prime}$-martensite during cold-rolling and tension. ${ }^{[15]}$ Deformation temperature is an important factor in the martensitic transformation of steels, as it was revealed that the occurrence of martensitic transformation is more pronounced at lower deformation temperatures. ${ }^{[21]}$

Martensite phase content significantly influences the mechanical properties of austenitic stainless steels. It was demonstrated ${ }^{[17,22,23]}$ that a larger amount of $\alpha^{\prime}$-martensite in steels led to a higher strain hardening, resulting in an increase in the flow stress and hardness and a reduction of the formability and ductility. ${ }^{[24]}$ Previous researches on $316 \mathrm{~L}$ and other TWIP steels postulated that the shapes of the tensile stress-strain curves were different at different testing temperatures. $^{[9,25-30]}$ The disparity among these curves was attributed to the different volume fractions of $\alpha^{\prime}$-martensite formed during deformation. Similarly, strain rate could also have considerable effect on the formation of $\alpha^{\prime}$-martensite during deformation and thus exhibit different stress-strain behaviors at different strain 
rates. $^{[31,32]}$ For example, the formation of a higher fraction of $\alpha^{\prime}$-martensitic phase was observed clearly at relatively higher stain rate $\left(10^{-3}\right.$ to $\left.10^{-2} \mathrm{~s}^{-1}\right)$ under tension. When the true strain was $50 \mathrm{pct}$, the volume fraction of $\alpha^{\prime}$-martensitic phase at higher strain rates $\left(10^{-3}\right.$ to $\left.10^{-2} \mathrm{~s}^{-1}\right)$ showed two-fold increase as compared to that at a lower strain rate of $10^{-4} \mathrm{~s}^{-1}$. [32]

The martensitic phase transformation can cause differences in the tensile and compression performances of $316 \mathrm{~L}$ steel, since this transformation is accompanied by a volume change. Namely, the transformation from $\gamma$-austenite to $\alpha^{\prime}$-martensite yields a volume increase of $\sim$ 2.6 pct, while that from $\gamma$-austenite to the intermediate $\varepsilon$-martensite results in a volume decrease of $\sim 0.8$ pct. ${ }^{[33]}$ Therefore, the development of the hard bcc $\alpha^{\prime}$-martensite is preferred during tension, which may lead to a higher strain hardening as compared to compression. It is noted that tension-compression asymmetry also occurs in other metallic materials, such as Al alloys. $^{[34-37]}$ The suggested reasons of this asymmetry are the residual stresses, the pressure dependence of the dislocation energy, and the texture. ${ }^{38-40]}$

Generally, the metastable austenite phase in steels transforms to martensite phases during mechanical loading. Such transformation is very beneficial for the mechanical behavior of steels as it significantly improves the work hardening and delays the onset of necking ${ }^{[41,42]}$ . This phenomenon is a known as a Transformation Induced Plasticity (TRIP) effect. TRIP steels possess a combination of high strength, good ductility, and improved toughness. ${ }^{[4,44]}$ The influence of the stress state and the deformation temperature on the evolution of the phase composition of TRIP steels was investigated using different loading modes, such as uniaxial tension, uniaxial compression, equi-biaxial tension, plane strain tension, and simple shear. ${ }^{[45]}$ It was found that the rate of martensitic transformation is the highest for plane strain tension, and gradually decreases in the order of equi-biaxial tension, uniaxial tension, and uniaxial compression. In addition, it was reported that the transformation from austenite to martensite becomes clearly slower with increasing deformation temperature. Furthermore, the hydrostatic pressure has a fundamental effect on the austenite to martensite transformation in TRIP steels. ${ }^{[46-48]}$ Pyshmintsev et $a .^{[47]}$ showed that the increase of the hydrostatic pressure yielded a remarkable improvement in all plastic characteristics occurred in TRIP steels.

Although the volume difference between austenite and martensite phases is an essential factor causing tension-compression asymmetry in steels, ${ }^{[49]}$ other effects, such as the different evolutions of lattice defects in the two deformation modes, may also play a significant role in the different stress-strain responses detected during tension and compression. In this paper, an in-depth study of the mechanical response obtained in tension and compression of a textured $316 \mathrm{~L}$ steel is presented, and the reasons of the tension-compression asymmetry are investigated in detail. The texture evolution, the change of the defect structure, and the evolution of the phase composition are studied up to the strain of 50 pct. It is also revealed that in addition to the different degrees of martensitic phase transformation, the disparate evolutions of the dislocation density play an important role in the tension-compression asymmetry of $316 \mathrm{~L}$ steel.

\section{MATERIAL AND METHODS}

The material used in the present study was an austenitic $316 \mathrm{~L}$ stainless steel. The chemical composition of this steel was Fe-17.20 pet $\mathrm{Cr}-8.97$ pet Ni-2.13 pet $\mathrm{Mo}-1.03$ pet $\mathrm{Mn}-0.77$ pet $\mathrm{Si}-0.48$ pet $\mathrm{Cu}-0.35$ pet $\mathrm{Co}$ (in wt pct) as obtained by energy-dispersive X-ray spectroscopy (EDS). The material was annealed at 1100 ${ }^{\circ} \mathrm{C}$ for 1 hour and then cooled to room temperature in water. This material was considered as the initial state in the present study. The initial material was produced in the form of bars. The schematic in Figure 1 shows a bar and the specimens cut from the bar for tensile and compression tests. The longitudinal direction of the tensile samples was parallel to the bar axis. The tensile specimens had a 10-mm gauge length, 5-mm width, and 1-mm thickness. The longitudinal axis of the compression specimens was perpendicular to the initial bar axis, as shown in Figure 1, because in this case contraction and extension of the material occur in directions TD and RD, respectively, similarly as for tension (the definitions of axes TD and RD are given in Figure 1). The compression specimens had a square-shaped cross section of $5 \mathrm{~mm} \times 5 \mathrm{~mm}$ and a $10-\mathrm{mm}$ length. The uniaxial tensile and compression tests were carried out by an MTS 810 universal mechanical testing machine at room temperature and a constant strain rate of $10^{-3} \mathrm{~s}^{-1}$. The true strain was determined as $\ln (1+e)$ for tension

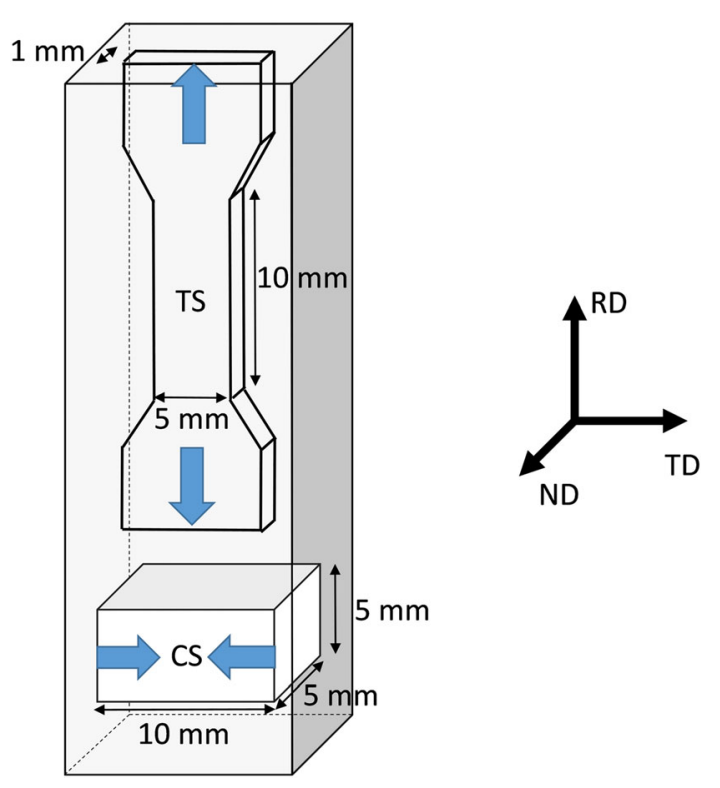

Fig. 1-Schematic diagram showing the cutting of specimens for compression and tension tests. The tension and compression samples are denoted as TS and CS, respectively. The blue arrows indicate the directions of the applied loads. The figure also shows the notations of the three axes used for the presentation of the results of the texture measurement. 
and $\ln \left(\frac{1}{1-e}\right)$ for compression, where $e$ is the engineering strain. The true plastic strain was obtained by removing the elastic strain component from the true strain which was determined on the basis of the initial linear elastic part of the stress-strain curve. The true stress was obtained as $\frac{F}{A_{0}}(1 \pm e)$, where $F$ is the applied force, $A_{0}$ is the initial cross section of the samples, and the plus and minus signs were applied for tension and compression, respectively. Both tension and compression were carried out for the true plastic strains of $\sim 25, \sim 45$, and $\sim 50$ pct. The latter value was selected as this was the highest strain before the onset of necking. Three experiments were performed for each strain value in order to check the reproducibility of the mechanical tests. In compression, the contact surfaces between the samples and the anvil were lubricated with $\mathrm{MoS}_{2}$; therefore, significant barreling during compression was not observed.

The evolutions of the microstructure and the phase composition during compression and tension were investigated by X-ray diffraction (XRD). The XRD measurements were carried out using a rotating anode diffractometer with $\mathrm{CoK} \alpha_{1}$ radiation (wavelength: $\lambda=$ $0.1789 \mathrm{~nm}$ ). The area-weighted mean crystallite size, the dislocation density, and the twin-fault probability in the main austenite phase were determined by X-ray line profile analysis (XLPA). The twin-fault probability gives the fraction of twin faults among the crystallographic planes $\{111\}$ and is determined as a percentage. In the XLPA procedure, the experimentally determined XRD patterns were fitted by theoretical profiles using the Convolutional Multiple Whole Profile (CMWP) fitting method. $^{[50]}$ These theoretical profile functions were calculated with the assumption that the peak broadening is caused by the finite crystallite size and two types of lattice defects (dislocations and twin faults).

The crystallographic texture of the initial and the deformed samples was examined by XRD pole figure analysis. The pole figures were measured in the RD-TD plane (see Figure 1) using a Smartlab X-ray diffractometer (manufacturer: Rigaku, Japan) with $\mathrm{CuK} \alpha$ radiation (wavelength: $\lambda=0.15418 \mathrm{~nm}$ ) and parallel-beam optics. Orientation distribution functions (ODFs) were calculated from the pole figures using software ATEX. ${ }^{[51]}$

The microstructures of the initial and the deformed specimens were also investigated using an FEI Quanta 3D scanning electron microscope (SEM). For the electron backscattered diffraction (EBSD) investigation, the studied surface was first mechanically polished with $\mathrm{SiC}$ abrasive papers. The final step in this mechanical polishing was performed with a 4000 grit paper; the polishing was then continued using colloidal silica suspensions (OP-S) with particle sizes of $1 \mu \mathrm{m}$ and 40 $\mathrm{nm}$. Finally, the mechanically polished surface was electropolished at $25 \mathrm{~V}$ and $1 \mathrm{~A}$ in an electrolyte consisting of 70 pct ethanol, 20 pct glycerine, and 10 pct perchloric acid (in vol. pct). In the EBSD experiments, the step sizes were $1 \mu \mathrm{m}$ and $100 \mathrm{~nm}$ for the images with lower and higher magnifications, respectively. The EBSD images were evaluated using the OIM software produced by TexSem Laboratories. Those areas were considered as grains that were bounded by high-angle grain boundaries (HAGBs) with misorientations higher than $15 \mathrm{deg}$. The area-weighted mean grain size was used for the characterization of the microstructure.

\section{RESULTS}

\section{A. Microstructure, Phase Composition, and Texture of the Initial Material}

The XRD pattern obtained for the initial material is shown in Figure 2. This sample is nearly a single-phase $\gamma$-austenite with only a small fraction of $\alpha^{\prime}$-martensite phase of $\sim 2$ pct as estimated from the ratio of the intensities diffracted from the two phases. This intensity was determined as the sum of the areas under the diffraction peaks of each phase after the background subtraction. Figure 3 shows EBSD orientation and phase maps for the initial sample, which also reveal that the initial material is almost a single-phase $\gamma$-austenite with a small amount of $\alpha^{\prime}$-martensite. The fraction of $\alpha^{\prime}$-martensite determined from the EBSD image $(\sim 1$ pct) was similar within error range to the value obtained by XRD. The average grain size of the main $\gamma$-austenite phase was $24 \pm 3 \mu \mathrm{m}$.

Figure 4 shows $\{111\},\{200\}$, and $\{220\}$ pole figures of the initial $316 \mathrm{~L}$ specimen measured in the plane RD-TD. The analysis of the pole figures shows that

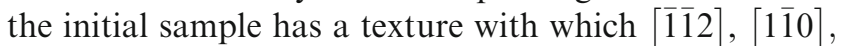
and [111] are nearly parallel to axes ND, TD, and RD, respectively, in most grains directions. The crystallographic orientation of the initial material is illustrated in Figure 5, which shows the relative orientation of the unit cell in the ND-TD-RD coordinate system. The right side of Figure 5 indicates that there is a scattering of direction [1112] in the ND-RD plane and the deviation between axis ND and direction [1112] can reach $40 \mathrm{deg}$. Accordingly, there is also a scattering of

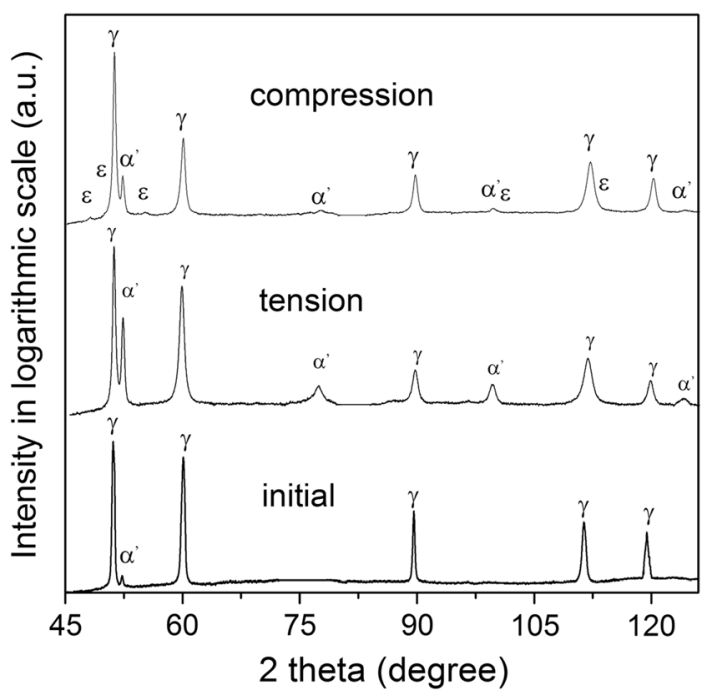

Fig. 2-XRD patterns obtained for the initial 316L steel and the samples deformed by compression and tension for the true strain of 50 pct. 

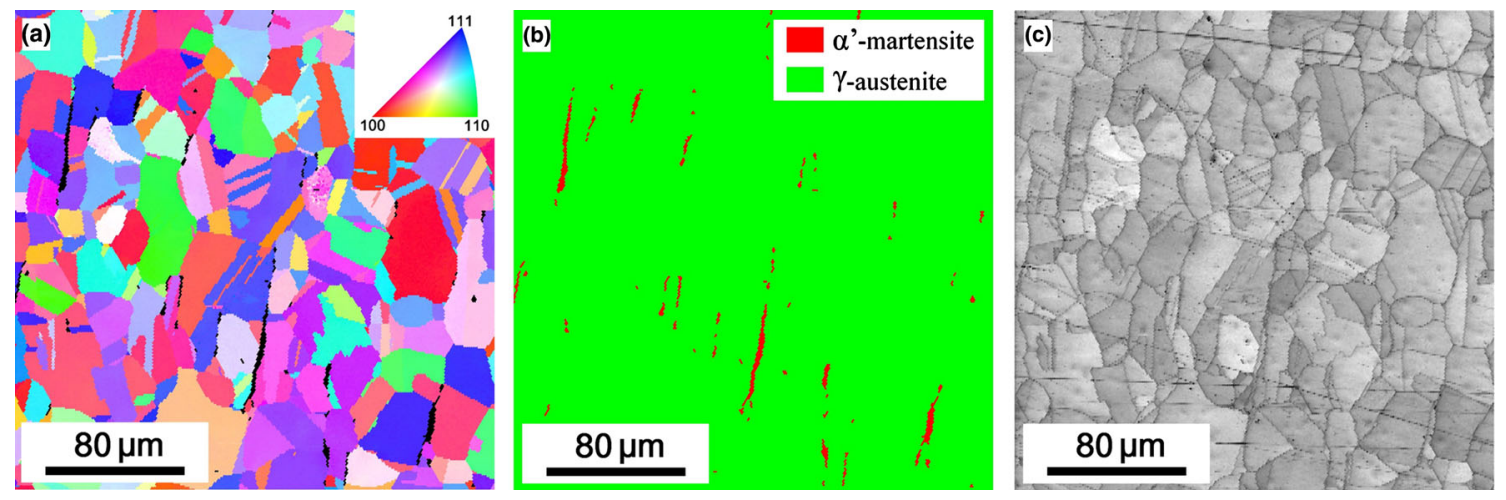

Fig. 3-EBSD orientation $(a)$, phase $(b)$ and image quality $(c)$ maps showing the microstructure for the initial $316 \mathrm{~L}$ specimen.
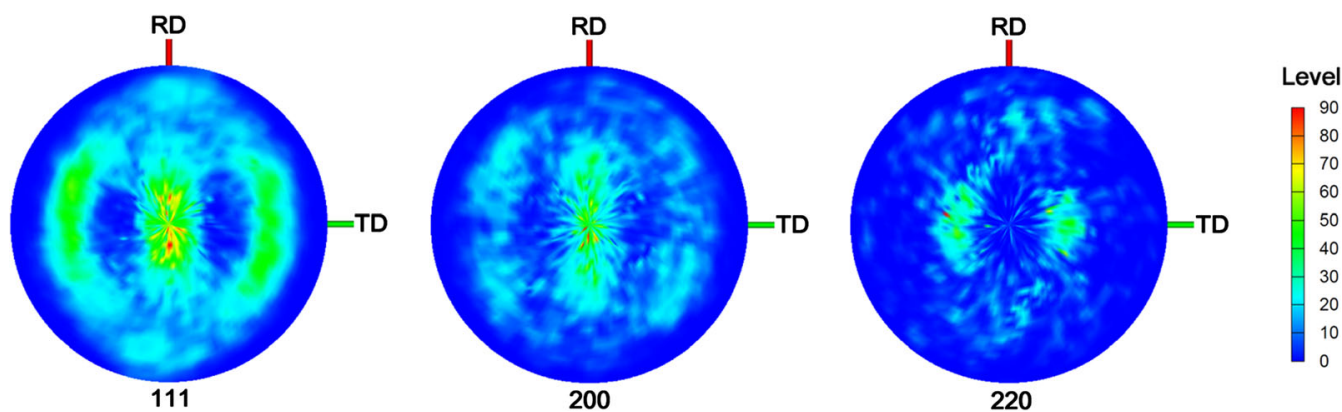

Fig. $4-\{111\},\{200\}$ and $\{220\}$ pole figures of the initial 316L specimen measured in the plane RD-TD (see Fig. 1).
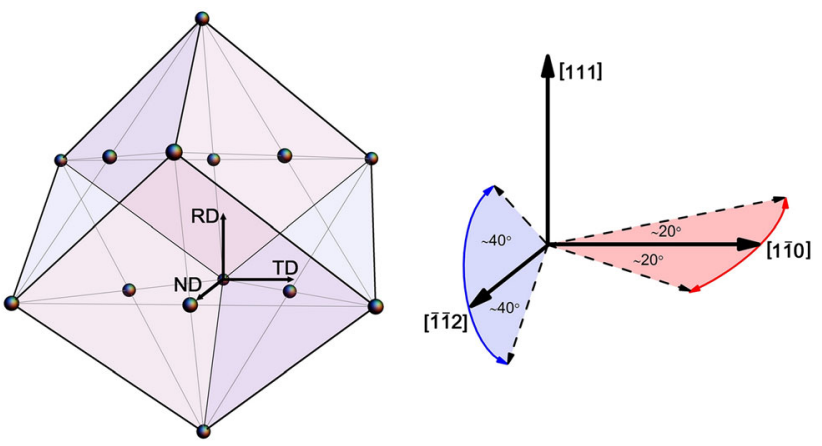

Fig. 5-The orientation of the fcc cell in the majority of grains of the initial sample relative to the ND-RD-TD coordinate system as obtained from the texture measurements (left). The scattering of the crystallographic orientations of the different grains is illustrated at the right side of the figure.

direction [111] around axis RD but this is not indicated in Figure 5. In addition, there is a scattering of direction $[1 \overline{1} 0]$ in the TD-ND plane, but the deviation between axis TD and direction $[1 \overline{1} 0]$ is not higher than $20 \mathrm{deg}$.

The ODF sections for the initial sample calculated from the pole figures for the Euler angles $\varphi_{2}=0$ and 45 deg are shown in Figure 6(a). The main texture component corresponding to the two high intensity spots in section $\varphi_{2}=45 \mathrm{deg}$ was identified as Copper for which the crystallographic directions $\langle 111\rangle$ and $\langle 112\rangle$ are parallel to the axes $\mathrm{RD}$ and $\mathrm{ND}$, respectively. This observation is in accordance with the schematic representation of the fcc cell orientation for the initial sample in Figure 5. The relatively large broadening of the two high intensity spots in the ODF is in line with the scattering of orientations $\langle 111\rangle$ and $\langle 112\rangle$ around the axes RD and ND, respectively. In addition to the main Copper texture component, a Cube component and other non-renowned components with low intensity were also identified. The ideal Euler angles and crystallographic orientations for the renowned rolling texture components, such as Copper or Cube, are listed in former papers. ${ }^{[52,53]}$ The volume fractions of the texture components were determined by software ATEX and are listed in Table I. In the initial sample, the main Copper component has a fraction of 88 pct. The volume fractions of the Cube and the other non-renowned components are about 3 and 9 pct, respectively.

\section{B. Tensile and Compressive Behaviors of the $316 \mathrm{~L}$ Stainless Steel Samples}

Representative true stress versus true plastic strain curves obtained by tension and compression are shown in Figure 7(a). Repeated measurements revealed that the statistical error of the stress values was lower than 5 pct. A very small difference between the tensile and compression curves was observed during the beginning of deformation up to true plastic strain of $\sim 25$ pct. For the tensile-tested specimen, the yield strength, the ultimate tensile strength, the uniform elongation, and the elongation to failure were $310 \pm 10,1230 \pm 30 \mathrm{MPa}, 50 \pm 2$ pct, and $55 \pm 3$ pct, respectively. On the other hand, during compression, the sample did not fail even at the 

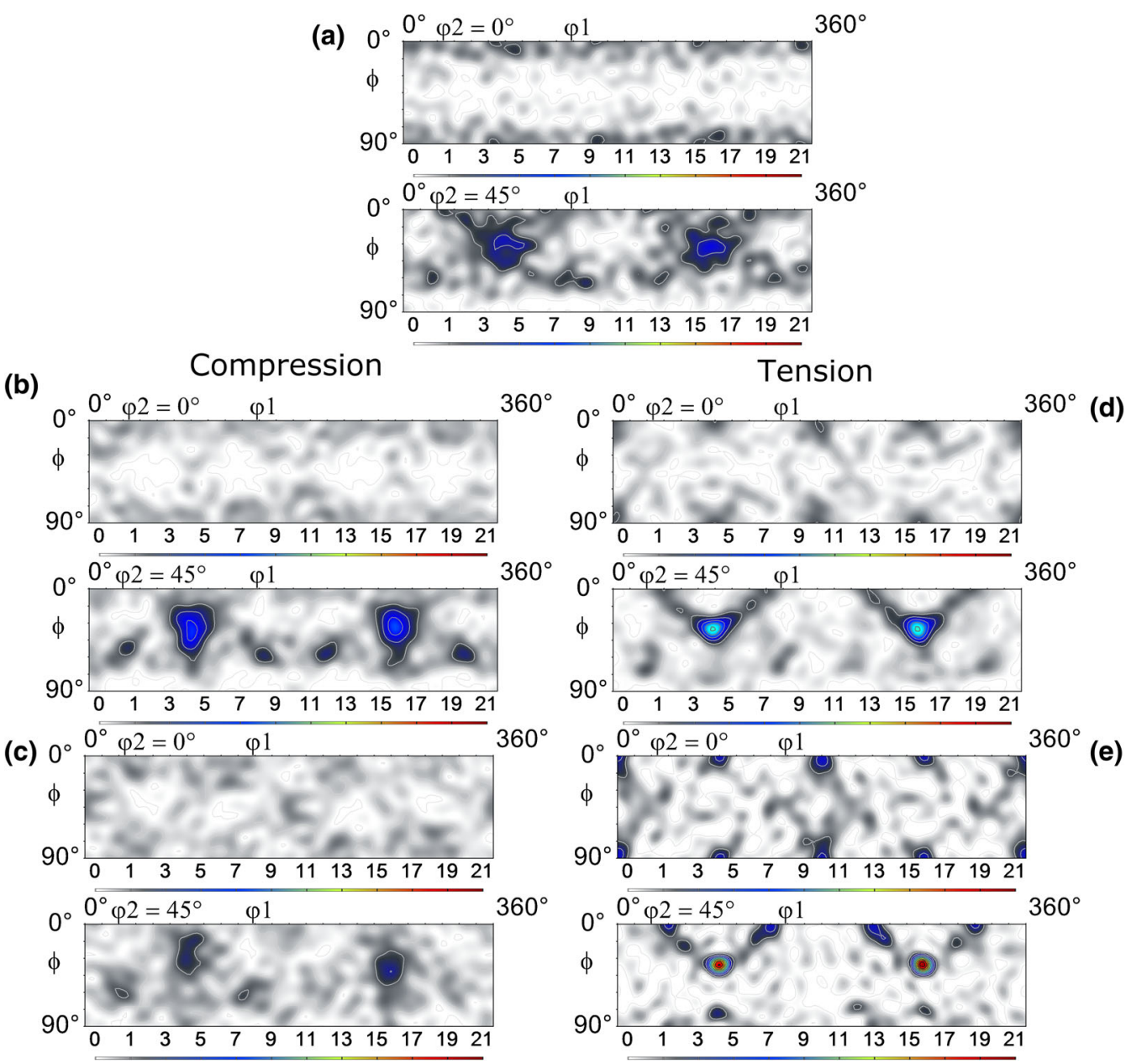

Fig. 6-ODF sections for the austenite phase in the initial 316L specimen $(a)$ in the samples deformed by compression $(b, c)$ and tension $(d, e)$ up to the true strains of 25 pct (b, d) and 50 pct (c, e).

Table I. The Texture Components and Their Fractions as Determined from the ODF Sections

\begin{tabular}{lccccc}
\hline \multirow{2}{*}{ Sample } & True Strain & \multicolumn{3}{c}{ Texture Components } \\
\cline { 3 - 6 } & & $\begin{array}{c}\text { Cube } \\
\{001\}\langle 100\rangle\end{array}$ & $\begin{array}{c}\text { Copper } \\
\{112\}\langle 111\rangle\end{array}$ & $\begin{array}{c}\mathrm{F} \\
\{11\}\langle 112\rangle\end{array}$ & Other Non-renowned \\
\hline Initial & 0 & 3 & 88 & 0 & 9 \\
Tension & $25 \mathrm{pct}$ & 3 & 97 & 0 & 0 \\
Tension & $50 \mathrm{pct}$ & 5 & 95 & 0 & 0 \\
Compression & $25 \mathrm{pct}$ & 0 & 99 & 0 & 6 \\
Compression & $50 \mathrm{pct}$ & 0 & 92 & 2 & 6 \\
\hline
\end{tabular}

true plastic strain of 130 pct; as the homogeneous deformation in tension ended at the strain of $\sim 50 \mathrm{pct}$, the stress-strain curve for compression is also shown only to this strain in Figure 7(a). The yield strength obtained by compression was $270 \pm 10 \mathrm{MPa}$ which is only $\sim 40 \mathrm{MPa}$ lower than that by tension. With increasing true plastic strain above 25 pct, the deviation between the tensile and compressive curves gradually increased. At 50 pct strain, the flow stress was 200 $\mathrm{MPa}$ higher for tension than for compression (see
Figure 7(a)). In order to reveal the microstructural reasons of this difference, the phase composition, the defect densities, and the texture of the tensile-tested and compressed samples were compared, as illustrated in the next sections.

Figure 7(b) shows the strain hardening rate versus the true stress (Kocks-Mecking plot) for tension and compression obtained as the derivative of the stressstrain curves plotted in Figure 7(a). The strain hardening rate monotonously decreases with increasing stress 


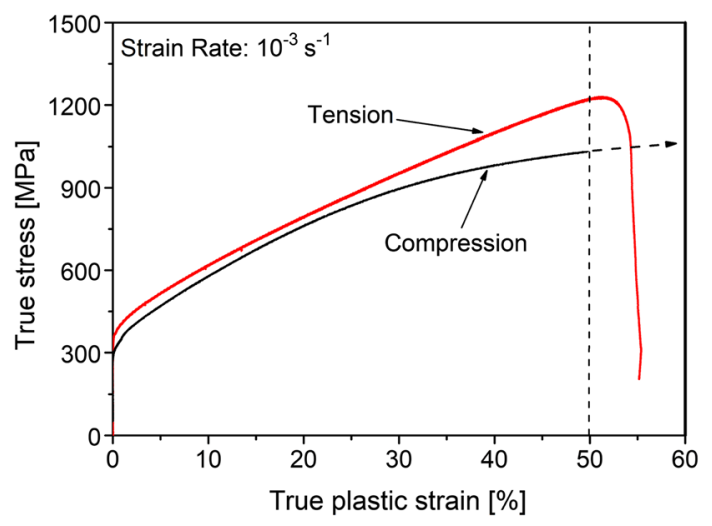

(a)

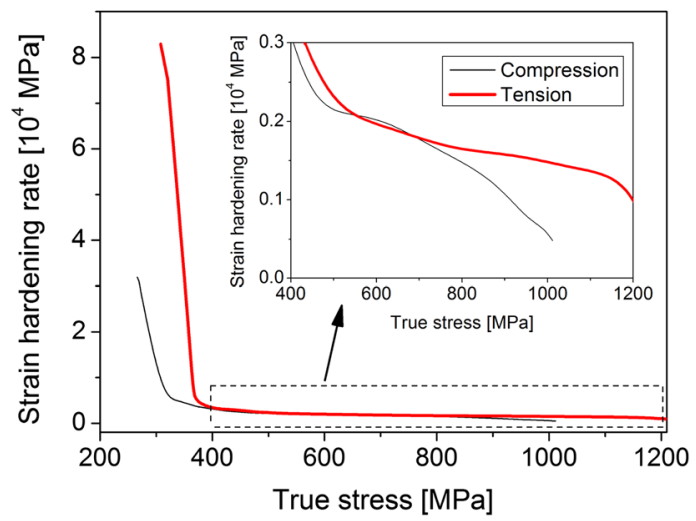

(b)

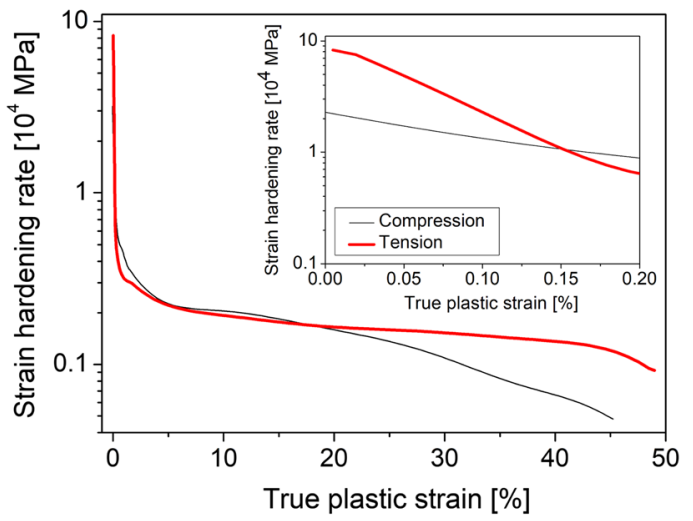

(c)

Fig. 7-(a) The true stress-true plastic strain curves for tension and compression of the studied $316 \mathrm{~L}$ steel samples. The dashed arrow indicates that compression was performed to higher strains (up to about $130 \mathrm{pct}$ ). (b) The strain hardening rate versus the stress for tension and compression (Kocks-Mecking plot). The inset shows a part of figure (b) related to low strain hardening values. (c) The strain hardening rate versus the true plastic strain for tension and compression. The inset shows a part of figure (c) related to low strain values.

for both tension and compression which is a typical behavior for fcc metallic materials. The onset of plastic deformation exhibited a high strain hardening rate (3000 to $8000 \mathrm{MPa}$ ) which decreased almost linearly to about $1000 \mathrm{MPa}$ when the stress increased to 300 to $400 \mathrm{MPa}$. Above the stress of 300 to $400 \mathrm{MPa}$, the decrease of the strain hardening rate continued up to the highest applied true stress values of 1000 to $1200 \mathrm{MPa}$, but this hardening rate reduction is much slower than that in the first stage of deformation (see Figure 7(b)). At the end of deformation (corresponding to the strain of $50 \mathrm{pct}$ ), the strain hardening rate decreased to about 50 to 100 $\mathrm{MPa}$ (see the inset of Figure 7(b)). Since the comparison between the microstructures developed during tension and compression will be made at the same strain values, the strain hardening rate was also plotted as a function of the true plastic strain in Figure 7(c). It can be seen that significant difference between the strain hardening rates for tension and compression was observed only at very small strains (below $0.15 \mathrm{pct}$ ) and above 20 pct. For both cases, tension exhibited a higher strain hardening rate compared to compression.

\section{Change of the Phase Composition During Tension and Compression as Obtained by XRD}

The change of the phase composition during the tensile and compression tests was investigated by XRD at 25 pct, 45 pct, and 50 pct strains. As an example, the XRD patterns obtained for the samples tensile-tested and compressed to true plastic strain of 50 pct are shown in Figure 2. For the compressed sample, in addition to the reflections of the main $\gamma$-austenite phase, diffraction peaks related to $\varepsilon$ - and $\alpha^{\prime}$-martensites are also observed. On the other hand, in the tensile-tested specimens, diffraction peaks of $\varepsilon$-martensite were not detected. Thus, during tension, the $\gamma$-austenite was transformed only to $\alpha^{\prime}$-martensite; in particular, the intensity of the $\alpha^{\prime}$-martensite peaks was much higher for tension than that for compression at the same strain.

Figure 8 shows the variation of the XRD intensity fraction of $\alpha^{\prime}$-martensite as a function of the true plastic strain for the tensile-tested and the compressed specimens. It can be seen that the amount of $\alpha^{\prime}$-martensite increases with increasing strain. Up to 25 pct strain, significant difference between the fractions of the $\alpha^{\prime}$-martensite phase in the tensile-tested and the

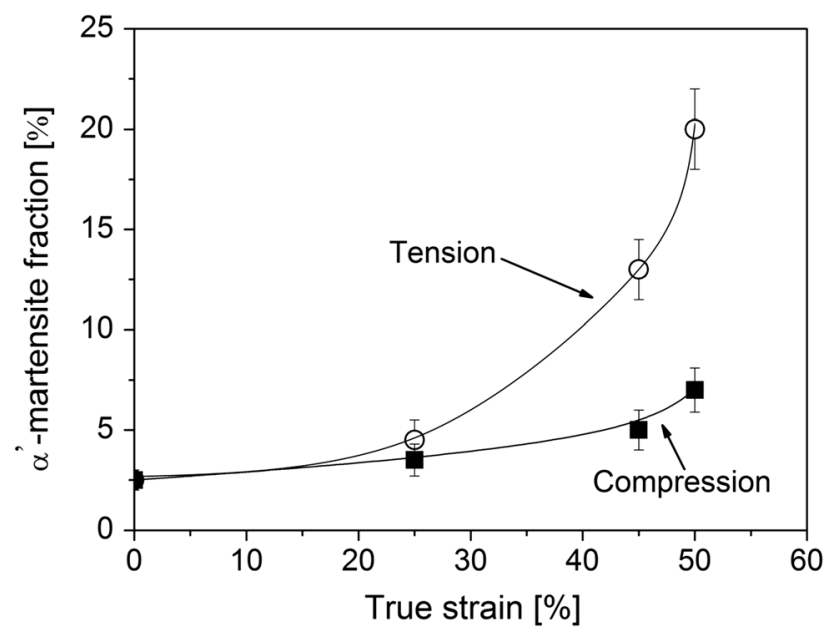

Fig. 8-The fraction of $\alpha^{\prime}$-martensite as function of true strain for compression and tension as determined from the intensities of the XRD peaks. 
compressed specimens was not found. In the tensile-tested sample, the fraction of $\alpha^{\prime}$-martensite reached $\sim 20$ pct at the true strain of 50 pct. At the same time, in compression, the fraction of $\alpha^{\prime}$-martensite slowly increased with increasing strain, and only $\sim 7$ pct was detected for the true strain of $\sim 50$ pct. It should be noted that a small fraction of $\varepsilon$-martensite was also observed in the compressed samples, increasing only to $\sim 2$ pct when the compressive strain reached 50 pct.

\section{EBSD Investigation of the Changes in the Phase Composition and the Boundary Structure}

Figures 9 and 10 show EBSD images taken on the tensile-tested and the compressed samples, respectively, at 50 pct strain. EBSD study for the strain of 25 pct was not conducted, since only slight differences were observed in the mechanical performances between tension and compression. The analysis of the EBSD images confirmed the difference in the phase composition of the two samples observed by XRD. The compressed specimen contains three phases $(\gamma$-austenite, $\varepsilon$-martensite, and $\alpha^{\prime}$-martensite), while only $\gamma$-austenite and $\alpha^{\prime}$-martensite were observed in the tensile-tested sample. In addition, the volume fraction of the phases determined by EBSD images is only slightly different from that estimated by XRD. It should be noted, however, that XRD measurement has better statistics than EBSD investigation. This difference can be explained by the $10^{3}$ to $10^{5}$-fold larger volume examined by XRD compared to that by EBSD. Therefore, in this paper, the volume fraction of the phases is characterized by the intensity ratio determined from the XRD patterns.

Table II shows the evolution of the amount of grain boundaries as obtained from the EBSD images taken on the initial material and the samples deformed by tension and compression up to 50 pct strain (see Figures 3, 9, and 10). The boundary length in a unit area was determined for three misorientation angle ranges corresponding to low- (2 to $5 \mathrm{deg}$ ), medium- (5 to $15 \mathrm{deg}$ ), and high-angle (15 to $60 \mathrm{deg}$ ) grain boundaries. Due to the low SFE of $316 \mathrm{~L}$ steel $\left(20 \mathrm{~mJ} / \mathrm{m}^{2[54]}\right)$, twin boundaries can form easily during the annealing step in the production of the initial material (formation of annealing twins) and also during subsequent plastic straining (deformation twinning). Therefore, the $\Sigma 3$ boundary length is also shown in Table II. In the initial sample, more than 90 pct of the boundaries have a high-angle character and about half of the high-angle boundaries are $\Sigma 3$ (twin) boundaries. Deformation to the strain of 50 pct increased the amount of all three types of grain boundaries. The total lengths of boundaries in a unit area increased from 0.181 to 1.899 and $1.871 \mu \mathrm{m}^{-1}$ after tension and compression, respectively. Despite these close values of the total boundary length, significant difference can be observed between the high-angle grain boundary length values between tension and compression up to 50 pet strain, with that after tension being significantly higher than that after compression. At the same time, the increase in the length of the medium-angle grain boundaries is more pronounced for compression.

\section{E. Evolutions of Crystallite Size, Dislocation Density, and Twin-Fault Probability During Tension and Compression}

The XLPA evaluation is illustrated in Figure 11, where the CMWP fitting on the XRD pattern taken on the sample compressed up to the strain of 50 pct is presented. Figure 12 shows the crystallite sizes and the
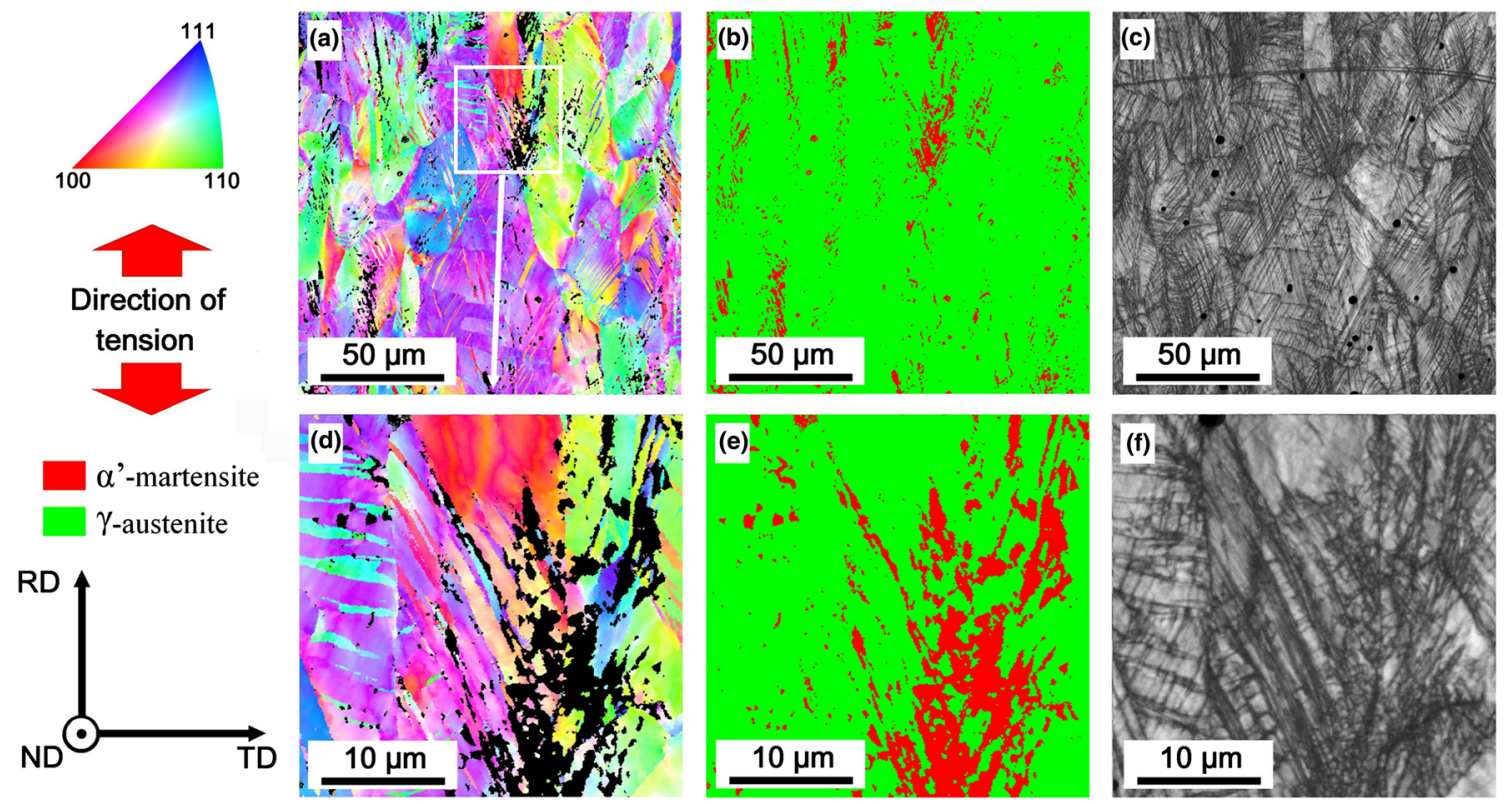

Fig. 9-EBSD orientation $(a)$, phase $(b)$, and image quality $(c)$ maps taken on the sample tested up to the true plastic strain of 50 pct by tension. Figure $(d)$ is a magnified part of the orientation map in (a), and $(e)$ and $(f)$ are the corresponding phase and image quality maps, respectively. 

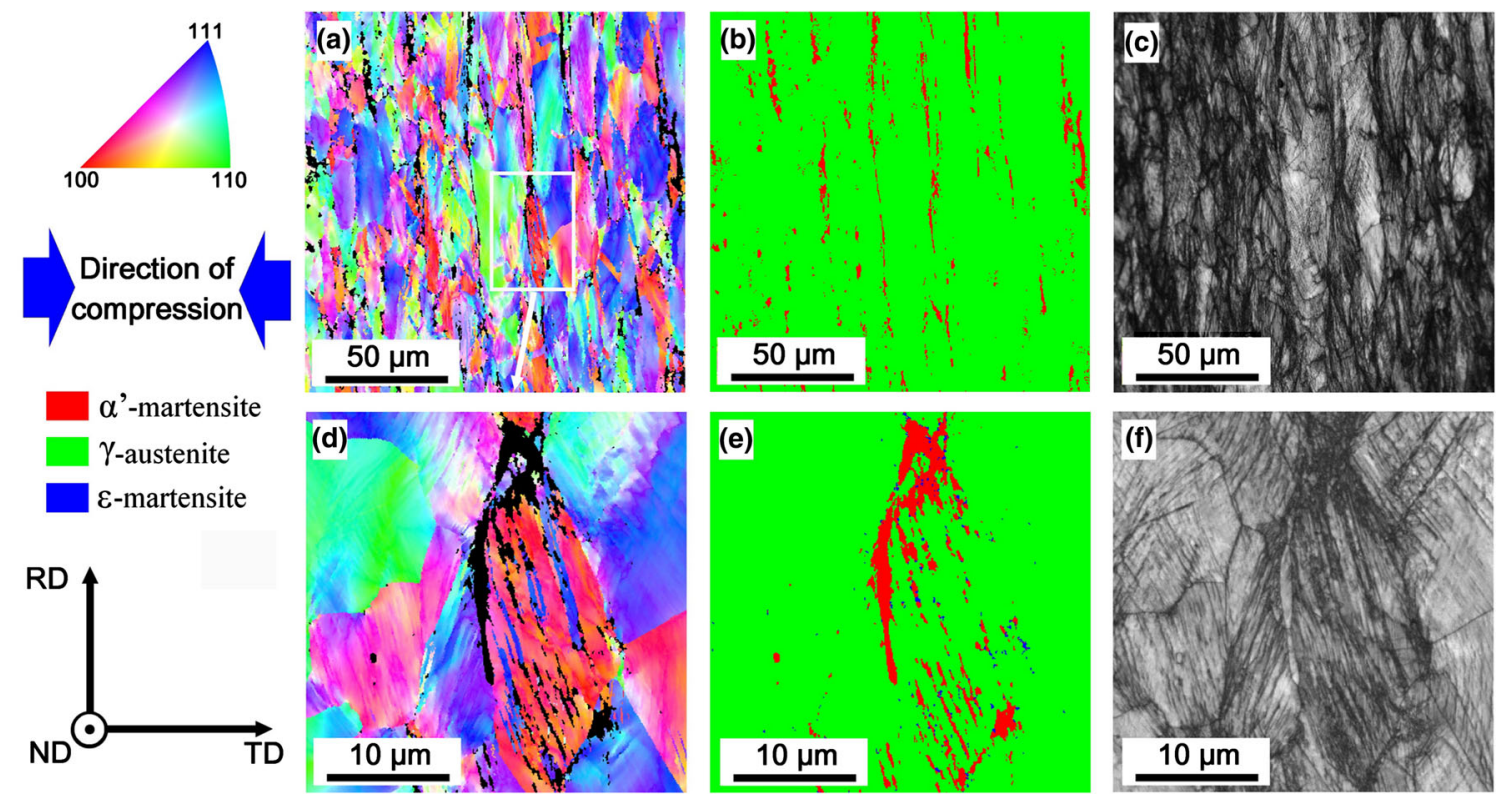

Fig. 10-EBSD orientation $(a)$, phase $(b)$, and image quality $(c)$ maps taken on the sample tested up to the true plastic strain of 50 pct by compression. $(d)$ is a magnified part of the orientation map in (a), and $(e)$ and $(f)$ are the corresponding phase and image quality maps, respectively.

dislocation densities obtained by XLPA as functions of true plastic strain for tension and compression. For the initial material, the crystallite size was larger, while the dislocation density was lower than the detection limits of XLPA $\left(\sim 800 \mathrm{~nm}\right.$ and $\sim 10^{13} \mathrm{~m}^{-2}$, respectively); therefore, for this sample data are not plotted in Figure 12. As a result of deformation, the order of magnitude of the dislocation density increased to $\sim 10^{15} \mathrm{~m}^{-2}$ even at $25 \mathrm{pct}$ strain. At this stage of deformation, no significant difference was observed between the values of the dislocation density in the samples deformed by compression and tension $\left(\sim 25 \times 10^{14} \mathrm{~m}^{-2}\right)$. However, a smaller crystallite size was obtained for the tensile-tested specimen as compared with the sample deformed by compression. With increasing strain, the dislocation density increased for both tension and compression samples. Between the strains of 25 and 50 pct, the dislocation density in the tensile-tested sample became gradually higher than that in the compressed specimen. At 50 pet strain, the dislocation density in the sample deformed by tension $\left(\sim 82 \times 10^{14} \mathrm{~m}^{-2}\right)$ was significantly higher than that in the compressed specimen $\left(\sim 56 \times 10^{14}\right.$ $\mathrm{m}^{-2}$ ). In addition, the crystallite size remained smaller in the tensile-tested sample. It should be noted that in plastically deformed materials the crystallite size obtained by XLPA is usually smaller than the grain size determined by microscopic methods, ${ }^{[55]}$ similar to the present case. This difference is due to the fact that XLPA measures the size of subgrains and/or dislocation cells, which is lower than the diameter of the grains. The twin-fault probability determined by XLPA increased from $0.1 \pm 0.1$ to $0.5 \pm 0.1$ pct when the strain increased from 25 to 50 pct for both tension and compression. It should be noted that in the present study it is not worth examining any correlation between the twin-fault probability obtained by XLPA and the amount of twin boundaries determined from the EBSD images, since the two methods are complementary to each other in the study of twinning. Specifically, XLPA is sensitive only to very fine twins, since this technique works well for the twin faults with the spacing smaller than $\sim 200 \mathrm{~nm}$. On the other hand, EBSD can visualize only coarse twins due to the applied resolution limit ( $1 \mu \mathrm{m}$ for the images taken on the larger areas and used for the evaluation of grain boundaries; see Figures 9 and 10).

\section{F. Change of the Crystallographic Texture During Tension and Compression}

The pole figures in Figure 13 illustrate the different evolutions of the crystallographic texture during tension and compression. Specifically, it shows the changes in pole figure $\{111\}$ during tension and compression for the true strains of 25 and 50 pct. It is evident that tension resulted in a sharpening of the texture-i.e., the scattering of direction [112] around the ND axis was reduced. An opposite trend was observed for compression, as the texture weakened and the range of the inclination angle between direction $[\overline{1} 12]$ and the ND axis increased, although for most grains direction [1112] remained in the ND-RD plane.

The ODF sections calculated for the austenite phase and shown in Figure 6 also confirm that the initial Copper main texture component was sharpened during tension while in compression this effect was not observed or rather the intensity spots of this component became broader. Table I reveals that the fraction of the main Copper texture component remained high for both tension and compression. During tension, the Cube component was also observed up to the strain of $50 \mathrm{pct}$ while in compression this component disappeared. At 
Table II. The Grain Boundary Length Normalized by the EBSD Image Area for Three Different Misorientation Angle Ranges in the Main $\gamma$-Austenite Phase of the Initial Sample and the Specimens Compression- and Tension-Tested Up To 50 pct Strain

\begin{tabular}{|c|c|c|c|c|c|}
\hline \multirow{2}{*}{ Sample } & \multirow{2}{*}{ True Strain } & \multicolumn{4}{|c|}{ Grain Boundary Length Per Unit Area $[1 / \mu \mathrm{m}]$} \\
\hline & & 2 to $5 \mathrm{deg}$ & 5 to $15 \mathrm{deg}$ & 15 to $60 \mathrm{deg}(\Sigma 3)$ & Total \\
\hline Initial & 0 & 0.007 & 0.006 & $0.168(0.088)$ & 0.181 \\
\hline Tension & $50 \mathrm{pct}$ & 1.173 & 0.206 & $0.520(0.084)$ & 1.899 \\
\hline Compression & $50 \mathrm{pct}$ & 1.100 & 0.398 & $0.373(0.020)$ & 1.871 \\
\hline
\end{tabular}

The length of $\Sigma 3$ boundaries is also indicated in the parenthesis.

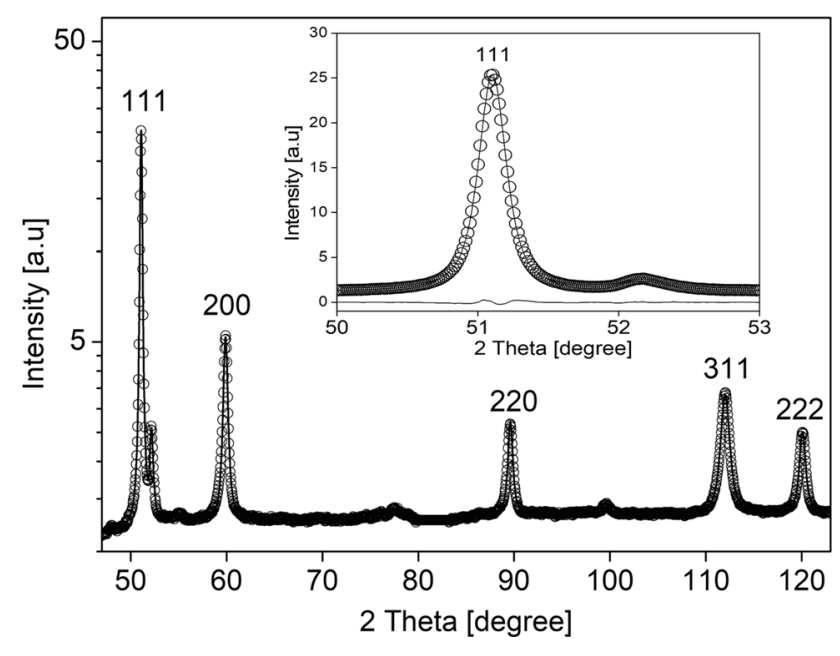

Fig. 11-CMWP fitting on the XRD pattern taken on the sample compressed up to the strain of $50 \mathrm{pct}$. The intensity is in logarithmic scale. The open circles and the solid line represent the measured and the fitted patterns, respectively. The inset shows a part of the diffractogram in linear intensity scale with a higher magnification. The difference between the measured and fitted diffractograms is shown at the bottom of the inset.

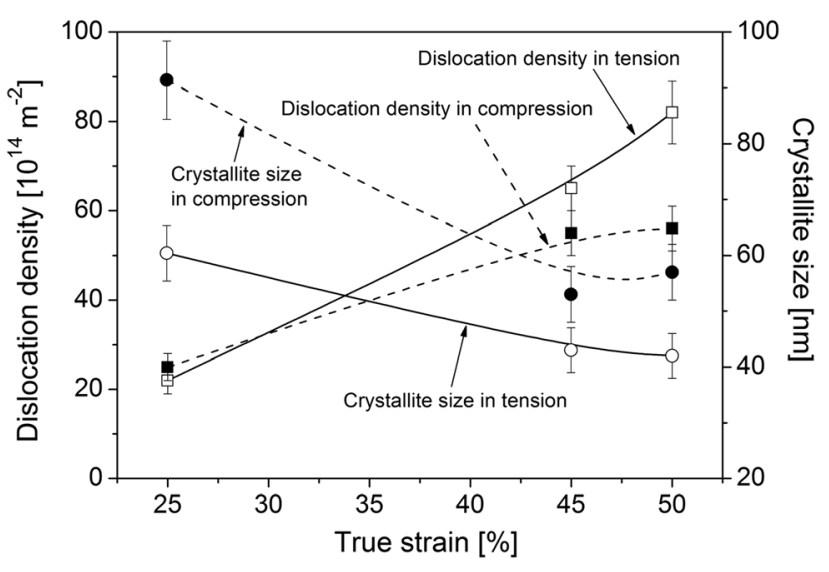

Fig. 12-The crystallite size and the dislocation density determined by XLPA in compressed and tensile-tested samples as a function of true strain.

the same time, in the samples compressed up to the strain of $50 \mathrm{pct}$ an $\mathrm{F}$ texture component developed with a very small fraction $(\sim 2$ pct $)$.

The fraction of $\alpha^{\prime}$-martensite phase increased to about 20 pct during tension performed up to the strain of 50 pct. Therefore, the texture of this phase was also investigated by pole figure measurements. The pole figures shown in Figure 14 indicate that considerable texture did not develop in the $\alpha^{\prime}$-martensite formed during tension. Thus, ODFs were not calculated and evaluated for this phase.

\section{DISCUSSION}

This study revealed a significant difference between the stress-strain behaviors of a coarse-grained $316 \mathrm{~L}$ steel tested by tension and compression (see Figure $7(\mathrm{a})$ ). In the beginning of deformation, the yield strength for tension was $\sim 40 \mathrm{MPa}$ larger than that for compression. This slight difference between their mechanical responses can be attributed to the different Schmid factors of the dislocation slip systems caused by the texture of the initial material. For the tension and compression tests, the deformation axes are nearly parallel to directions [111] and [110], respectively. For uniaxial deformation of fcc crystals in directions [111] and $[1 \overline{1} 0]$, the Schmid factors of the active slip systems are 0.272 and 0.408 , respectively, as determined from the formula $m=\cos \alpha \times \cos \beta$, where $\alpha$ is the angle between the loading axis and the slip direction, while $\beta$ is the angle between the loading axis and the slip plane normal. Therefore, the tension along axis [111] requires higher stress than that for compression parallel to the direction $[1 \overline{1} 0]$. Since there is a scattering of the tensile and compression axes around directions [111] and [1 10$]$ (see Figure 5), the difference between the yield strength values in the present tension and compression experiments is lower than that suggested by the Schmid factors given above for the ideal [111] and $[1 \overline{1} 0]$ textures.

Up to 25 pct strain, the difference between the flow stresses for tension and compression remained low and was caused only by the texture, since both the dislocation density in the main fcc austenite and the martensite content were close between the two deformation modes (see Figures 8 and 12). At the same time, between the 25 and 50 pct strains, tension required a higher flow stress, which can be attributed at least partly to the higher dislocation density in the fcc phase. Of course, the texture-sharpening during tension also contributes to the higher flow stress than that for compression. The higher dislocation density developed during tension can be attributed to the much lower Schmid factors in the tensile-tested sample compared to the compressed specimen, as discussed below. Between 25 and 50 pct strains, 


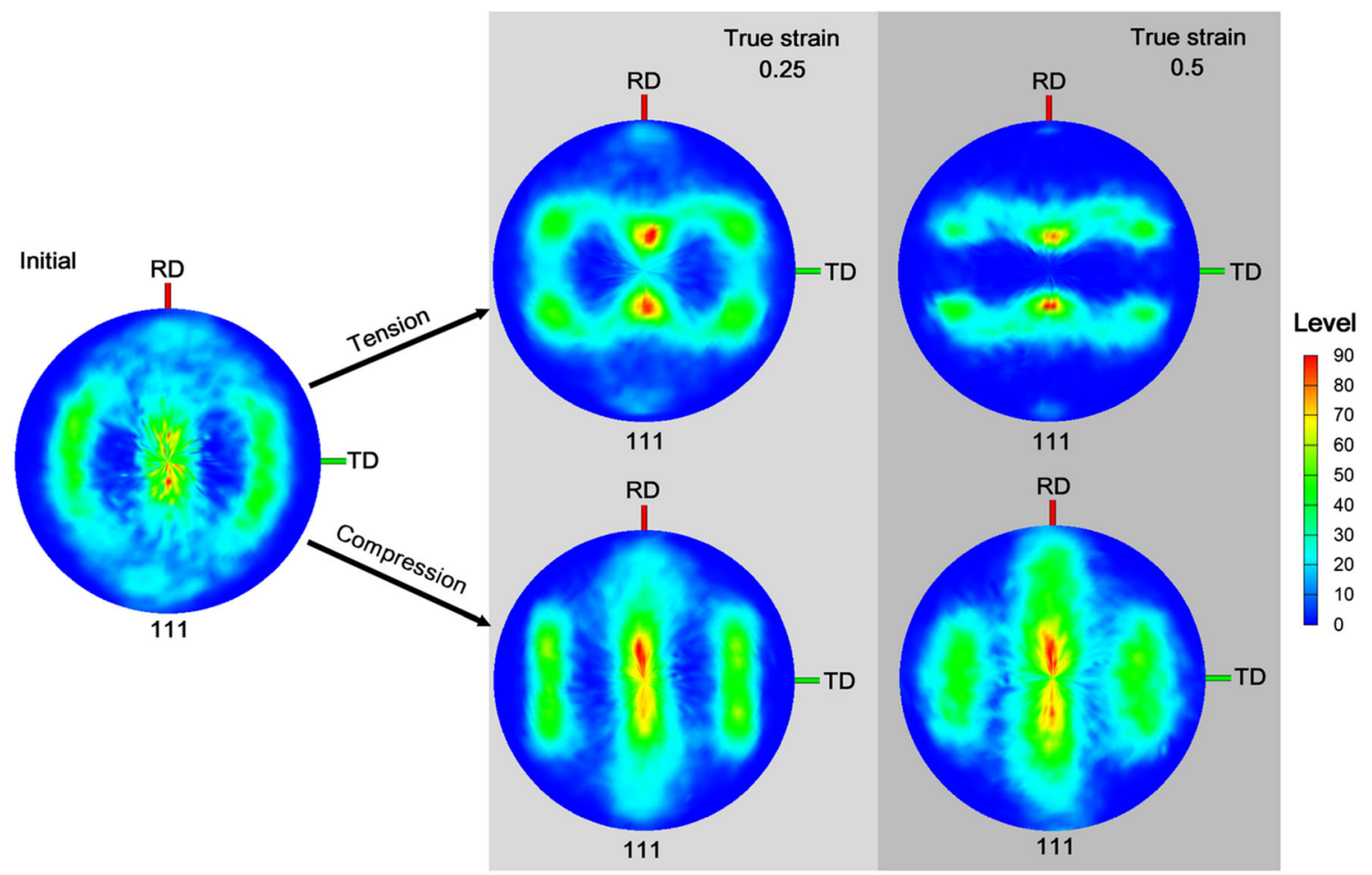

Fig. 13-The evolution of the $\{111\}$ pole figure during tension and compression up to the true strain of 50 pct.

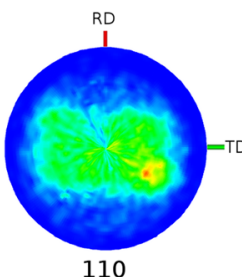

110

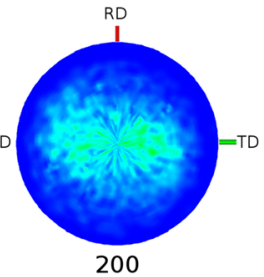

200

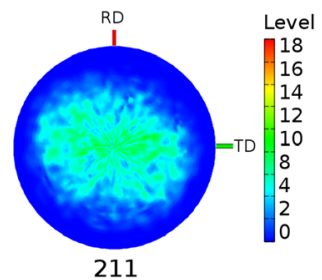

211

Fig. $14-\{110\},\{200\}$, and $\{211\}$ pole figures measured in the plane RD-TD for the $\alpha^{\prime}$-martensite phase in the specimen tensile tested up to the strain of 50 pct.

texture-sharpening was observed during tension, in which the direction [111] became parallel to the tensile axis for most grains. In this case, there are six active slip systems with equal Schmid factors, of 0.272. At the same time, in compression a fiber-like texture was developed, in which the deformation axis was parallel to direction $[1 \overline{1} 0]$. It should be noted that there is a scattering of direction $[1 \overline{1} 0]$ around axis TD (see Figures 5 and 13) - i.e., this texture is not very sharp. Nevertheless, in the calculation of the Schmid factors for the compressed sample, a perfect fiber texture was assumed. In this case, four slip systems were activated with Schmid factors of 0.408 . The Schmid factor of an active slip system $(m)$ determines the relationship between the shear strain $(\gamma)$ in the glide plane and its contribution to the measured plastic strain $(\varepsilon)$ as ${ }^{[56]}$ :

$$
\varepsilon=m \gamma
$$

The shear strain can be expressed with the density of gliding dislocations in the slip system $\left(\rho_{\mathrm{SS}}\right)$ as ${ }^{[57]}$ :

$$
\gamma=\rho_{\mathrm{SS}} b s
$$

where $b$ is the magnitude of the Burgers vector and $s$ is the average gliding distance of dislocations. For multiple slip systems with equal Schmid factors $(m)$, the plastic strain can be expressed using Eqs. [1] and [2] as

$$
\varepsilon=m n \rho_{\mathrm{SS}} b s
$$

where $n$ is the number of active slip systems. If we neglect the scattering of the direction [110] around the compression axis TD, the values of $n$ for tension and compression at large strains equal 6 and 4, respectively. The product of $n \rho_{S S}$ gives the total dislocation density, denoted as $\rho$. Since the magnitude of the Burgers vector does not differ between tension and compression, the same strain in the two deformation modes corresponds to the same value of $m \rho s$. As the number of slip systems is higher for tension than for compression, the formation of glide obstacles due to the interaction between the dislocations gliding on different slip planes is more probable for tension. Therefore, the average gliding distance of dislocations $(s)$ should be lower for tension, and the Schmid factor is also lower for this deformation mode. Thus, a higher dislocation density is necessary for achieving the same plastic strain during tension in the present study. It should be emphasized that this explanation is obtained with a simplification of the observed crystallographic textures; therefore, it is not suitable for a precise calculation of the quantitative difference between the dislocation densities formed at high strains during tension and compression. The higher probability 
of the formation of glide obstacles for tension due to the texture can explain the higher initial strain hardening rate as compared to compression (see Figure 6(c)).

It should be noted that the influence of the texture on the yield strength can also be explained by the Taylor model. In this case, uniform deformation of all grains and five activated slip systems are assumed. The values of the Taylor factor calculated from the Taylor model are equal (3.674) in directions [111] and [110]; therefore, we would not expect difference between the yield strength values measured in tension and compression. It seems that in the present case the texture effect on the yield strength can be better described by the Schmid factor analysis given in this study. However, it is worth to emphasize that in the present Schmid factor analysis multiple slip was assumed, i.e., not the unrealistic Sachs model was applied which assumes only single slip in each grain.

The higher flow stress for tension at 50 pct strain can be explained partly by the significantly larger $\alpha^{\prime}$-martensite fraction compared to the compressed sample. The $\alpha^{\prime}$-martensite phase has a bcc structure, which is usually harder than the fcc structure with the similar chemical composition, thereby increasing the flow stress of the material. The higher $\alpha^{\prime}$-martensite fraction for tension can be attributed at least partly to the higher dislocation density. Namely, the $\alpha^{\prime}$-martensite particles are often nucleated at glide obstacles, such as Lomer-Cottrell locks and grain boundaries, where the internal stresses are high. Since the dislocation density at 50 pet strain was higher for tension than that for compression, the probabilities of formation of Lomer-Cottrell locks and dislocation pile-ups at grain boundaries were also higher. Thus, a higher fraction of $\alpha^{\prime}$-martensite was developed during tension up to 50 pet strain.

The higher volume fraction of $\alpha^{\prime}$-martensite during tension for the strains higher than 25 pct can explain the higher strain hardening rate as compared to compression. Indeed, former studies have proved a correlation between the strain hardening rate and the evolution of $\alpha^{\prime}$-martensite in stainless steels. ${ }^{[58,59]}$ Namely, when the rate of $\alpha^{\prime}$-martensite formation increased as a function of strain, the strain hardening rate also increased ${ }^{[58]} \mathrm{In}$ the beginning of deformation, the increase of $\alpha^{\prime}$-martensite fraction often has a low rate but the $\gamma$-austenite $\rightarrow$ $\alpha^{\prime}$-martensite transformation rate can increase suddenly to a higher value with increasing strain. ${ }^{[59]}$ In this case, the initial region of the stress-strain curve is characterized with a slowly rising stress which then strongly increases when the volume fraction of $\alpha^{\prime}$-martensite is enhanced. The appearance of this plateau on the tensile stress-strain curve depends on the chemical composition of the studied austenitic stainless steel, the strain rate, and the temperature of tension. ${ }^{[59-62]}$ The slowly rising stress range was detected in the literature mainly for 301, 302 , and 304 types of stainless steel at tension temperatures lower than $-15^{\circ} \mathrm{C} .{ }^{[59,61,62]} \mathrm{In}$ our case, plateau was not observed on the stress-strain curves which can be attributed to the fact that we studied $316 \mathrm{~L}$ steel at room temperature.
It should be noted that former studies reported that $\gamma$-austenite $\rightarrow \alpha^{\prime}$-martensite transformation caused a volume increase of $\sim 2.6 \mathrm{pct}$, while the transformation to $\varepsilon$-martensite led to a volume decrease of $\sim 0.8$ pct in $316 \mathrm{~L}$ steel. ${ }^{[33,63]}$ Accordingly, the $\gamma$-austenite $\rightarrow$ $\alpha^{\prime}$-martensite phase transformation is not preferred under compressive loading requiring a large increase in volume, whereas the direct transformation from $\gamma$-austenite to $\alpha^{\prime}$-martensite is preferred under tensile loading. In contrast, the $\gamma$-austenite $\rightarrow \varepsilon$-martensite transformation readily occurs under the compressive loading; however, it is hindered in tensile loading. These features of the martensitic transformation may also contribute to the higher fraction of $\alpha^{\prime}$-martensite after tension at 50 pet strain, as well as the appearance of $\varepsilon$-martensite during compression.

The higher dislocation density promoted a more pronounced refinement of the microstructure during tension than during compression. This effect is revealed by the higher amount of high-angle grain boundaries in the tensile-tested sample up to 50 pct strain (see Table II). As high-angle grain boundaries are preferred nucleation sites for $\alpha^{\prime}$-martensite, the larger amount of these boundaries in the tensile-tested sample may have contributed to the higher $\alpha^{\prime}$-martensite fraction at large strains. The higher dislocation density also facilitated the development of twin boundaries as the nucleation of twins requires high stresses, which usually develop at dislocation pile-ups. The more pronounced refinement of the microstructure during tension was also indicated by the smaller crystallite size.

It is noted that differences between compressive and tensile performances have already been observed for different metallic materials in the literature. For instance, tension-compression asymmetry was reported for S30403 austenitic stainless steel. ${ }^{[64]}$ At the same time, the studied S30403 steel exhibited a higher strain hardening during compression than during tension. A somewhat different behavior was observed in the present study, which can be attributed to the different textures in the two materials and the unique loading mode in our investigations. In other words, during our experiments, the tensile and compression axes were perpendicular in order to achieve extension in direction RD and contraction in direction TD for both tension and compression. In the literature, the tensile and compressive axes are usually parallel. Furthermore, a tension-compression asymmetry was also found in Al-Fe-Cr-Ti alloy, ${ }^{[39]}$ 304L austenitic stainless steel processed by equal channel angular pressing (ECAP) at $700{ }^{\circ} \mathrm{C}^{[34]}$ and $\mathrm{Fe}-10 \mathrm{Cu}$ alloy. ${ }^{[65]}$

It should also be noted that the difference in the stress states during tension and compression may have an effect on the different evolutions of martensite fraction. A former study has shown that the stress state considerably influences the martensitic start temperature. ${ }^{[66]}$ For both tension and compression, this temperature linearly increased with increasing the stress level. However, for the same stress value the increase of the martensitic start temperature is larger for tension than for compression. Therefore, the occurrence of 
martensitic transformation is easier for tension. It was also shown that the hydrostatic pressure reduced the martensitic start temperature as the external pressure acts against the volume expansion due to martensitic phase transformation. ${ }^{[66]}$

The present results revealed that the higher flow stress observed at high strains during tension can be attributed partly to the more pronounced austenite $\rightarrow$ martensite phase transformation. A difference between the martensitic phase transformations occurring during tensile and compression tests was also observed for $\mathrm{Fe}-0.4 \mathrm{C}-18 \mathrm{Mn}$ steel. ${ }^{[49]}$ In that material system, a transformation sequence of $\gamma$-austenite $\rightarrow \varepsilon$-martensite $\rightarrow \alpha^{\prime}$-martensite occurred during tension at $-196{ }^{\circ} \mathrm{C}$, while after the compression test, only $\varepsilon$-martensite was found (i.e., no $\alpha^{\prime}$-martensite). In present study, $\varepsilon$-martensite was observed only with a small fraction after compression together with a considerable amount of $\alpha^{\prime}$-martensite. This difference in the phase evolution can be attributed to the different chemical compositions of the materials and the very different deformation temperatures used between the present study and literature. It is noted that some investigations in the literature have stated that the formation of $\varepsilon$-martensite is a prerequisite for the nucleation of $\alpha^{\prime}$-martensite, ${ }^{[7,17,67]}$ while other works reported that $\alpha^{\prime}$-martensite can form independently of $\varepsilon$-martensite. ${ }^{[11,15,24]}$ The direct phase transformation from $\gamma$-austenite to $\alpha^{\prime}$-martensite observed for tension in this study is in agreement with the result obtained previously for cold-rolled $316 \mathrm{~L}$ stainless steel tested by tension. ${ }^{[15]} \mathrm{It}$ was also reported that the fraction of $\alpha^{\prime}$-martensite in 316 stainless steel increased exponentially with increasing true strain in rolling. ${ }^{[11]}$ At the same time, another work also suggested a practically unchanged low fraction $(<1 \mathrm{pct})$ of $\alpha^{\prime}$-martensite in the 316 stainless steel as a function of the true strain up to 50 pct in tension, revealing the importance of deformation mode in phase transformation. ${ }^{[68]}$ This observation strongly deviates from the present finding, as in our case the martensite phase fraction showed a fast increase with increasing tensile strain. This difference can be explained by the different carbon contents of the two materials: the previously investigated sample contained 0.06 wt pct carbon (316 steel), while our 316L steel specimen contains a carbon content $<0.03$ wt pct. Indeed, a previous study showed that the addition of carbon atoms to stainless steel stabilizes the fcc austenite. ${ }^{[69]}$ The evolution of the $\alpha^{\prime}$-martensite fraction in our investigation rather resembles the exponential trend observed for cold-rolled 316 steel. Nevertheless, the present study revealed that although different fractions of $\alpha^{\prime}$-martensite were developed between tension and compression of textured $316 \mathrm{~L}$ steel, the different evolutions of the dislocation density also contributed to the various stress-strain behaviors between the two deformation modes. The higher strain hardening rate for tension at strains higher than 25 pct (see Figure 7(c)) can be attributed to the higher rate of the increase of the dislocation density and the martensite fraction as compared to compression.

\section{CONCLUSIONS}

The evolutions of the microstructure and the stressstrain behavior during tension and compression of a coarse-grained $316 \mathrm{~L}$ stainless steel were compared. The maximum applied true plastic strain was 50 pct. The following conclusions have been drawn from the results:

1. The studied $316 \mathrm{~L}$ stainless steel showed a tension-compression asymmetry. Namely, the yield strength was higher by $\sim 40 \mathrm{MPa}$ for tension due to the texture of the initial material, since the loading axes during tension and compression were nearly parallel to the crystallographic directions [111] and $[1 \overline{1} 0]$, respectively. The main texture component was identified as Copper. Between 25 and 50 pct strains the flow stress during tension gradually became much higher than that for compression. At the strain of $50 \mathrm{pct}$, the difference between the flow stresses reached the value of $\sim 200 \mathrm{MPa}$.

2. The dislocation density increased from less than $10^{13} \mathrm{~m}^{-2}$ to $\sim 25 \times 10^{14} \mathrm{~m}^{-2}$ during both tension and compression up to the strain of 25 pct. Between 25 and 50 pet strains, the increase of the dislocation density was higher for tension than that for compression. Indeed, the dislocation densities were enhanced to $\sim 82 \times 10^{14} \mathrm{~m}^{-2}$ and $\sim 56 \times 10^{14}$ $\mathrm{m}^{-2}$ after tension and compression, respectively, performed up to the strain of 50 pct. This difference can also be explained by the different loading directions between the tensile-tested and compressed samples. In other words, due to the lower Schmid factors of the slip systems in the tensile-tested specimen, more dislocations were necessary for achieving the same strain.

3. The higher dislocation density resulted in a more pronounced refinement of the microstructure during tension, which was manifested as the larger amount of high-angle grain boundaries in the tensile-tested sample. A significant portion of these boundaries were twin boundaries. The higher dislocation density and the larger amount of high-angle grain boundaries most probably contributed to the higher fraction of $\alpha^{\prime}$-martensite in the tensile-tested sample because the martensite grains are favorably nucleated at grain boundaries due to high stresses, which may be caused by dislocation pile-ups at glide obstacles, such as Lomer-Cottrell locks and grain boundaries.

4. Between 25 and 50 pet strains, in addition to the different evolutions of the defect densities in the two deformation modes, a different martensitic phase transformation was also observed. Namely, $\gamma$-austenite was transformed into $\alpha^{\prime}$ - and $\varepsilon$-martensites under compression load, while only $\alpha^{\prime}$-martensite was formed during tensile test. Moreover, the amount of $\alpha^{\prime}$-martensite increased at a higher rate with increasing strain in the tensile-tested specimen. At 50 pct strain, the martensitic phase fraction reached 20 pct in tension but only 7 pct in compression. The difference between the martensite phase fractions in tension and compression was 
explained by the different dislocations densities as the high stresses at dislocation pile-ups promote the nucleation of martensite grains. In addition, the volume expansion and contraction during the formation of $\alpha^{\prime}$ - and $\varepsilon$-martensites, respectively, should have also contributed to the observed difference in phase transformation.

5. The tension-compression asymmetry of the studied 316L stainless steel was attributed to the different phase compositions, textures, and dislocation densities developed during tension and compression.

\section{ACKNOWLEDGMENTS}

Open access funding provided by Eötvös Loránd University (ELTE). This work was supported in part by the Ministry of Human Capacities of Hungary within the ELTE University Excellence program (1783-3/2018/ FEKUTSRAT). HC acknowledges support from the Korea Electric Power Corporation (Grant No.: R18XA06-41).

\section{DECLARATIONS OF INTEREST}

None

\section{DATA AVAILABILITY}

The raw/processed data required to reproduce these findings cannot be shared at this time due to technical or time limitations.

\section{OPEN ACCESS}

This article is licensed under a Creative Commons Attribution 4.0 International License, which permits use, sharing, adaptation, distribution and reproduction in any medium or format, as long as you give appropriate credit to the original author(s) and the source, provide a link to the Creative Commons licence, and indicate if changes were made. The images or other third party material in this article are included in the article's Creative Commons licence, unless indicated otherwise in a credit line to the material. If material is not included in the article's Creative Commons licence and your intended use is not permitted by statutory regulation or exceeds the permitted use, you will need to obtain permission directly from the copyright holder. To view a copy of this licence, visit http://creativecomm ons.org/licenses/by/4.0/.

\section{REFERENCES}

1. Y. Kim, Y. Kim, D. Kim, S. Kim, W. Nam, and H. Choe: Mater. Trans., 2011, vol. 52, pp. 507-13.

2. S. Wang, J. Li, Y. Cao, B. Gao, Q. Mao, and Y. Li: Vacuum, 2018, vol. 152, pp. 261-4.

3. R.K. Desu, K.H. Nitin, A. Balu, A.K. Gupta, and S.K. Singh: J. Mater. Res. Technol., 2016, vol. 5, pp. 13-20.

4. L. Zhang and J. Wang: J. Nucl. Mater., 2014, vol. 446, pp. 15-26.

5. A.U. Malik, S. Ahmad, and I. Andijani: Desalination, 1999, vol. 123 , pp. $205-13$.

6. F.V. Anghelina, D.N. Ungureanu, V. Bratu, I.N. Popescu, and C.O. Rusanescu: Appl. Surf. Sci., 2013, vol. 285, pp. 65-71.

7. J. Gubicza, M. El-Tahawy, Y. Huang, H. Choi, H. Choe, J.L. Lábár, and T.G. Langdon: Mater. Sci. Eng. A, 2016, vol. 657, pp. 215-23.

8. Y. Mine, Z. Horita, and Y. Murakami: Acta Mater., 2009, vol. 57, pp. 2993-3002.

9. K. Spencer, M. Véron, K. Yu-Zhang, and J.D. Embury: Mater. Sci. Technol., 2009, vol. 25, pp. 7-17.

10. H.F.G. De Abreu, S.S. De Carvalho, P. De Lima Neto, R.P. Dos Santos, V.N. Freire, P.M.D.O. Silva, and S.S.M. Tavares: Mater. Res., 2007, vol. 10, pp. 359-66.

11. V. Shrinivas, S.K. Varma, and L.E. Murr: Metall. Mater. Trans. A, 1995, vol. 26A, pp. 661-71

12. M. Eskandari, A. Najafizadeh, and A. Kermanpur: Mater. Sci. Eng. A, 2009, vol. 519, pp. 46-50.

13. S. Scheriau, Z. Zhang, S. Kleber, and R. Pippan: Mater. Sci. Eng. $A$, 2011, vol. 528, pp. 2776-86.

14. S. Martin, S. Wolf, U. Martin, L. Krüger, and D. Rafaja: Metall. Mater. Trans. A, 2016, vol. 47A, pp. 49-58.

15. J.D.E.K. Spencer, M. Véron, and K. Yu-Zhang: Mater. Sci. Technol., 2009, vol. 25, pp. 7-17.

16. G.B. Olson and M. Cohen: J. Less-Common Met., 1972, vol. 28, pp. 107-18.

17. A.K. De, J.G. Speer, D.K. Matlock, D.C. Murdock, M.C. Mataya, and R.J. Comstock: Metall. Mater. Trans. A, 2006, vol. $37 \mathrm{~A}$, pp. $1875-86$.

18. J.A. Venables: Philos. Mag., 1962, vol. 7, pp. 35-44

19. A.J. Bogers and W.G. Burgers: Acta Metall., 1964, vol. 12, pp. 255-61.

20. R. Lagneborgj: Acta Metall., 1964, vol. 12, pp. 823-43.

21. C. Herrera, R.L. Plaut, and A.F. Padilha: Mater. Sci. Forum, 2007, vol. 550, pp. $423-28$.

22. A.K. De, J.G. Speer, D.K. Matlock, D.C. Murdock, M.C. Mataya, and R.J. Comstock: Metall. Mater. Trans. A, 2006, vol. $37 \mathrm{~A}$, pp. $1875-86$.

23. L. Krüger, S. Wolf, U. Martin, S. Martin, P.R. Scheller, A. Jahn, and A. Weiß: J. Phys. Conf. Ser., 2010, vol. 240, p. 012098.

24. P.M. de O. Silva, H.F.G. d. Abreu, V.H.C. d. Albuquerque, P. de L. Neto, and J.M.R.S. Tavares: Mater. Des., 2011, vol. 32, pp. $605-14$.

25. S. Curtze and V.T. Kuokkala: Acta Mater., 2010, vol. 58, pp. $5129-41$.

26. M. Calmunger, G. Chai, R. Eriksson, S. Johansson, and J.J. Moverare: Metall. Mater. Trans. A, 2017, vol. 48A, pp. $4525-38$

27. X. Wu, X. Pan, J.C. Mabon, M. Li, and J.F. Stubbins: J. Nucl. Mater., 2006, vol. 356, pp. 70-77.

28. A. Talgotra, E. Nagy, M. Sepsi, M. Benke, and V. Mertinger: IOP Conf. Series: Materials Science and Engineering, 2018, vol. 426, article no. 012046

29. F. De Barbieri, F.C. Cerda, J. Pérez-Ipiña, A. Artigas, and A. Monsalve: Metals, 2018, vol. 8, article no. 262.

30. Z. Tang, J. Huang, H. Ding, Z. Cai, D. Zhang, and D. Misra: Metals, 2018, vol. 8, article no. 476

31. S.S. Hecher, M.G. Stout, K.P. Staudhammer, and J.L. Smith: Met. Trans. A, 1982, vol. 13, pp. 619-26. 
32. P. Hedstrom, L.E. Lindgren, J. Almer, U. Lienert, J. Bernier, M. Terner, and M. Oden: Met. Mater. Trans. A, 2009, vol. 40A, pp. 1039-48.

33. A.F. Padilha, R.L. Plaut, and P.R. Rios: ISIJ Int., 2003, vol. 43, pp. $135-43$.

34. S. Qu, C.X. Huang, Y.L. Gao, G. Yang, S.D. Wu, Q.S. Zang, and Z.F. Zhang: Mater. Sci. Eng. A, 2008, vol. 475, pp. 207-16.

35. G.G. Yapici, I. Karaman, Z.P. Luo, H.J. Maier, and Y.I. Chumlyakov: J. Mater. Res., 2004, vol. 19, pp. 2268-78.

36. C.Y. Yu, P.L. Sun, P.W. Kao, and C.P. Chang: Scripta Mater., 2005, vol. 52, pp. 359-63.

37. B.Q. Han, E.J. Lavernia, and F.A. Mohamed: Mater. Sci. Eng. A, 2003, vol. 358, pp. 318-23.

38. S. Cheng, J.A. Spencer, and W.W. Milligan: Acta Mater., 2003, vol. 51, pp. 4505-18.

39. H. Luo, L. Shaw, L.C. Zhang, and D. Miracle: Mater. Sci. Eng. A, 2005, vol. 409, pp. 249-56.

40. K. Gall: Int. J. Plast., 1999, vol. 15, pp. 69-92.

41. E. Girault, A. Mertens, P. Jacques, Y. Houbaert, B. Verlinden, and J. Van Humbeeck: Scripta Mater., 2001, vol. 44, pp. 885-92.

42. N. Tsuchida, Y. Morimoto, T. Tonan, Y. Shibata, K. Fukaura, and R. Ueji: ISIJ Int., 2011, vol. 51, pp. 124-29.

43. X.L. Wu, M.X. Yang, F.P. Yuan, L. Chen, and Y.T. Zhu: Acta Mater., 2016, vol. 112, pp. 337-46.

44. E.R. Parker and V.F. Zackay: Eng. Fract. Mech., 1973, vol. 5, pp. 147-65.

45. H. Kim, J. Lee, F. Barlat, D. Kim, and M.G. Lee: Acta Mater., 2015, vol. 97, pp. 435-44.

46. J.R. Patel and M. Cohen: Acta Metall., 1953, vol. 1, pp. 531-38.

47. I.Y. Pyshmintsev, M. De Meyer, B.C. De Cooman, R.A. Savray, V.P. Shveykin, and M. Vermeulen: Metall. Mater. Trans. A, 2002, vol. 33A, pp. 1659-67.

48. S.V. Radcliffe and M. Schatz: Acta Metall., 1962, vol. 10, pp. 201-07.

49. H. Kim, J. Park, Y. Ha, W. Kim, S.S. Sohn, H.S. Kim, B.J. Lee, N.J. Kim, and S. Lee: Acta Mater., 2015, vol. 96, pp. 37-46.

50. G. Ribárik, J. Gubicza, and T. Ungár: Mater. Sci. Eng. A, 2004, vols. 387-389, pp. 343-47.

51. B. Beausir, J.-J. Fundenberger: Analysis Tools for Electron and X-ray diffraction, ATEX - software, www.atex-software.eu, Université de Lorraine - Metz, 2017.
52. Y. Zhou, K.W. Neale, and L.S. Tóth: Acta Metall. Mater., 1991, vol. 39, pp. 2921-30.

53. Y. Zhou, L.S. Tóth, and K.W. Neale: Acta Metall. Mater., 1992, vol. 40, pp. 3179-93.

54. G. Meric de Bellefon, J.C. van Duysen, and K. Sridharan: J. Nucl. Mater., 2017, vol. 492, pp. 227-30.

55. J. Gubicza: Defect Structure and Properties of Nanomaterials, 2nd ed., Woodhead Publishing, Duxford, 2017, pp. 27-93.

56. K. Bowman: Mechanical Behavior of Materials, Wiley, Hoboken, 2003, pp. 1-368.

57. H.J. Frost and M.F. Ashby: Deformation-Mechanism Maps: The Plasticity and Creep of Metals and Ceramics, Pergamon Press, Oxford, 1982, pp. 1-166.

58. C. Celada-Casero, H. Kooiker, M. Groen, J. Post, and D. SanMartin: Metals, 2017, vol. 7, article no. 271.

59. J.L. dos Santos, S.N. Monteiroa, V.S. Cândido, A.O. da Silvaa, and F.J. Tommasini: Mater. Res., 2017, vol. 20, pp. 596-602.

60. J. Talonen, H. Hänninen, P. Nenonen, and G. Pape: Metall. Mater. Trans. A, 2005, vol. 36A, pp. 421-32.

61. S.S. Hecker, M.G. Stout, K.P. Staudhammer, and J.L. Smith: Metall. Trans. A, 1982, vol. 13, pp. 619-26.

62. K. Al-Fadhalah and M. Aleem: Metall. Mater. Trans. A, 2018, vol. 49A, pp. 1121-39.

63. A.A. Lebedev and V.V. Kosarchuk: Int. J. Plast., 2000, vol. 16, pp. 749-67.

64. Y. Peng, J. Chu, and J. Dong: Materials (Basel), 2018, vol. 11, pp. 1023-34.

65. J.E. Carsley, A. Fisher, W.W. Milligan, and E.C. Aifantis: Metall. Mater. Trans. A, 1998, vol. 29a, pp. 2261-71.

66. H.N. Han, C.G. Lee, C.-S. Oh, T.-H. Lee, and S.-J. Kim: Acta Mater., 2004, vol. 52, pp. 5203-14.

67. V. Seetharaman and R. Krishnan: J. Mater. Sci., 1981, vol. 16, pp. 523-30.

68. S.K. Varma, J. Kalyanam, L.E. Murk, and V. Srinivas: J. Mater. Sci. Lett., 1994, vol. 13, pp. 107-11.

69. S. Karewar, J. Sietsma, and M. Santofimia: Crystals, 2019, vol. 9, pp. $99-112$.

Publisher's Note Springer Nature remains neutral with regard to jurisdictional claims in published maps and institutional affiliations. 